\title{
Videoculturas de la japoanimación
}

Por Rafael del Villar Muñoz

\author{
Introducción
}

La Agenda Setting de los Medios Masivos reitera, en el contexto chileno, una preocupación de Padres y Educadores por el contenido violento de muchas de las series animadas japonesas más vistas por los niños y jóvenes. Sin embargo, no existen muchos estudios científicos al respecto, y es por ello que la Unidad de Videoanimación del Departamento de Investigaciones Mediáticas y de la Comunicación, y Escuela de Periodismo, de la Universidad de Chile, realiza una investigación más amplia (Proyecto Fondecyt No 1000954) sobre la materia, y de la cual sintetizaremos aquí fragmentos exploratorios de la investigación en curso.

\section{Japoanimación y consumo cultural}

La japoanimación tiene una presencia en la cultura masiva chilena consiguiendo los más altos rating de consumo televisivo en niños y jóvenes. Según un estudio estadístico del Consejo Nacional de Televisión, en una muestra estratificada de 1176 niños de 7 a 13 años, de la Ciudad de Santiago, se señala que las actividades preferidas en los días de semana son en un 28,0 \% ver Televisión o Video, contra jugar o salir a jugar con un $29,1 \%$. Las otras prioridades son, entre otras de índole decreciente, hacer tareas 7,4 \%, hacer deporte 6,5 \%, etc. Esto es, la Televisión en todos los segmentos socioeconómicos, con o sin TV Cable, y cualquiera sea el género, constituye un objeto de consumo cotidiano apreciado por los niños. Ahora bien, los niños que prefieren jugar son más numerosos en 20 año básico (6 o 7 años), a diferencia de los niños de 50 Básico (8- 9 años), y de 10 Medio (12-13 años) que prefieren ver Televisión o Video. Los Domingos la Televisión y/o el Video constituyen la tercera preferencia. "En general el consumo televisivo crece al aumentar el curso de los niños: los niños de 20 básico presentan un promedio de 121 minutos, los de 5 o básico uno de 125 minutos, y los de 10 medio ven en promedio 154 minutos diarios de televisión" (Consejo Nacional de Televisión, 1999: pág. 39). Los programas más vistos (en todas las edades, en todos los segmentos socioeconómicos, y en todos los géneros), según la encuesta citada del Consejo Nacional de Televisión, son: en un 53,6 \% los dibujos animados, en un $14,1 \%$ las telenovelas, en un $6,7 \%$ las películas, en un 5,0 \% los programas culturales, en un $4,9 \%$ los video- clip, en un 3,9\% los programas infantiles, en un 2,9\% deportes, en un 2,1 \% series, etc. De ellos, "los resultados del análisis cualitativo muestran que los niños de 20 y 50 básico (6 a 9 años) prefieren mayoritariamente dibujos animados, especialmente aquellos de animación japonesa: Dragón Ball y Sailor Moon. En esta elección se distinguen claramente las opciones de hombres y mujeres: los hombres prefieren mayoritariamente Dragón Ball y las mujeres Sailor Moon" (Consejo Nacional de Televisión, 1999: pág. 43); lo que es independiente del segmento socioeconómico, y de la posesión o no de TV Cable. Las razones para preferir un programa son: "entretenido/ divertido" 66,6\%; "enseñan/ interesantes" 9,0\%, "otros motivos" 8,3\%, "por la violencia/ enseña a pelear" 5,7 \%, "características técnicas del programa" 3,6 \%, "no son reales" 1,8 \%, "me emociona" 1,6\%, "tienen cosas en común conmigo" 1,5\%, "son realistas" 0,6 $\%$. Las razones para elegir un programa u otro son, entonces, las mismas que para ver televisión, la "entretención". Es importante constatar que "la violencia o enseñar a pelear" es un criterio que se plantea en cuarta importancia, pero dentro de un contexto de $5,7 \%$, frente a un 66,6 \% que implica la razón "entretención"; lo que contrasta con el hecho de que los programas que se señalan como los más vistos, según los estudios del Consejo Nacional de Televisión (1999), son los más violentos: Dragón Ball y Sailor Moon. Esto implicaría que no es la violencia el criterio que se toma en cuenta para elegir un programa u otro, sino la entretención. Luego, podríamos tener la hipótesis de que no se le asigna al programa un contenido de realidad, las categorías "son realistas" y "no son reales" suman apenas un 2,4. Ahora bien, ¿qué significa entretención?, y ¿qué relación tiene con la comprensión? Según la encuesta "los programas más fáciles de comprender son los dibujos animados en un 47,9 \%; todo lo que está en español en un $10,2 \%$, los programas infantiles o educativos en un $8,8 \%$; y las telenovelas en un $5 \%$. Un 8,5 \% de los niños señalaron que todos los programas les resultan fáciles de comprender", (Consejo Nacional de Televisión, 1999: 66). Esto es, la "entretención" 
estaría ligado a la "comprensión", por lo que podría pensarse que "Dragón Ball y Sailor Moon" tendrían una sintaxis simple, lo que entraría en contradicción con Películas y Seriales, entre otros, que tendrían una estructura compleja. Sin embargo, esto no es así, precisamente Dragón Ball y Sailor Moon tienen semióticamente una estructura compleja, según nuestros estudios ya realizados.

Por otra parte, podría pensarse que los protocolos de lectura de los niños serían simbólicos, al interior de la conceptualización de Metz (1977) y Aumont- Marie $(1985,1988)$, entendidos como identificación con roles, valores e ideas. Las investigaciones cuantitativas del consejo detectan las siguientes variables de lectura respecto a los personajes: "características personales de los personajes" 16,5 \%, "características respecto a lo deseable socialmente" 9,0 $\%$, "análisis de los efectos concretos centrados en las consecuencias" 39,1\%, "análisis respecto a las reglas culturales rígidas de lo establecido" 20,6\%, "análisis respecto a principios o valores universales" 14,8 \%. Esto es, la lectura no dice relación con el personaje en sí mismo, hecho ya detectado teóricamente por Aumont- Marie (1985), tampoco conductas socialmente consideradas como deseables (status, belleza, éxito, etc.), sino que mayoritariamente (un $39,1 \%$ ) aquello que dice relación con los efectos de las conductas; y sólo, en segundo lugar las cosmovisiones e ideologías (que en total suman un 35,4 5). Efectos de las conductas", que en el caso del Dragón Ball y Sailor Moon no son reales, se trata de un espacio ficcional. Se preguntó a los niños respecto al miedo, y un $82,3 \%$ dijo haber sentido miedo en las películas o series, un $5,9 \%$ en las noticias, y sólo un $4 \%$ en los dibujos animados. Se preguntó, también sobre la rabia: un $31,6 \%$ en teleseries, un $22,6 \%$ en películas o series, un $13,5 \%$ en noticias, y sólo un $13,3 \%$ en dibujos animados. Respecto a la pena, las películas o series producen pena en un $47,5 \%$, las teleseries en un $19 \%$, las noticias un $12,5 \%$, y sólo en un $8,6 \%$ los dibujos animados. El miedo, la rabia y la pena parecen no estar ligados estrechamente a los dibujos animados, lo que implicaría la necesidad de inteligibilizar semióticamente estos espacio ficcionales pues los sentimientos narrativos respecto a la acción se asocian a otros géneros televisivos no a la videoanimación. Por otra parte, es un hecho que la japoanimación es un tipo de dibujo animado violento, sin embargo, cuando se le pregunta a los niños por la violencia en la televisión, ellos nombran como primera frecuencia a las películas, en un 43,0 $\%$, en segunda instancia a los dibujos animados, en un $25,5 \%$, y en tercera instancia a las noticias, en un $16,0 \%$. Esto podría significar, hipotéticamente que mayoritariamente se ve la existencia de violencia en las películas, y no en los dibujos, pues son ficción, pero como, desde otro punto de vista, es cierto que hay violencia en la japoanimación, se dice que existe violencia en un $25,5 \%$. Es claro, que entender esta problemática requiere de una inteligibilización semiótica del nuevo espacio planteado por la japoanimación; pues siendo los dibujos animados más vistos violentos, lo normal sería una respuesta del tipo: los dibujos animados japoneses, un $59 \%$. Sin embargo, iporqué hay un $43 \%$ que no le asigna violencia a la japoanimación? Según las respuestas dadas con anterioridad por los niños, podríamos deducir que por que se trata de un espacio de ficción, de allí que no genere ella ni rabia, ni pena, ni miedo, y sí los otros géneros televisivos. Desde esa perspectiva la respuesta del 25,5 $\%$ que señala haber violencia en los dibujos, podría ser una simple constatación empírica, incoherente con el protocolo empírico de lectura, pero sí coherente con responder al entrevistador que busca una respuesta a partir de una pregunta. Respecto a la identificación, los personajes a los que a los niños les gustaría parecerse son preferentemente personas $(65,2$ $\%)$, y en un 37,9 \% ficcionales. Esto implica que se torna importante detectar semióticamente: ¿qué significa este espacio ficcional?, ¿qué significa este gusto o entretención de la japoanimación?, ¿cuál es concretamente el proceso identificatorio que de la japoanimación emerge? Los datos cuantitativos no nos hablan de que una identificación simbólica y/o valórica sea preponderante, pero un $35,4 \%$ tienen una identificación próxima o asimilable a una identificación simbólica, en la conceptualización de Lacan (1966, 1973, 1981), Kristeva (1974, 1980, 1983), Metz (1977), y Aumont- Marie (1985, 1988): ¿qué significa este $35,4 \%$ de identificación próxima a una identificación simbólica?, ¿qué significa este protocolo de lectura basado en los efectos concretos centrados en la consecuencia de las acciones?

Contestar estas interrogantes no es posible a través de un estudio cuantitativo; sino que se requiere reconstruir, a través de sucesivas entrevistas en profundidad, historias de vida, realización de dibujos y/o comics, cuestionarios abiertos, un modelo semiótico interpretativo de los diferentes protocolos empíricos de lectura de los niños.que debe validarse 
etnográficamente. La Japoanimación no agota el formato del video- televisivo, sino que se interconecta con el Comic, Internet, Compac Disc, CD Rom, Video- Juegos, más una gama variada de objetos de marchandising. Lo singular de la japoanimación es la presencia de tiendas y toda una red de acciones sociales que giran en torno a ella, realizadas por jóvenes que fluctúan entre 6 y 18 años, de carácter heterogéneo etaria y socioeconómicamente. Se crea una micro- cultura, donde su tronco de referencia social es la televisión, pero no entrega ella un hilo conductor, un único mito de referencia simbólico, sino que él se construye a partir de una serie de fragmentos, con relaciones secuenciales muy disímiles: la televisión entrega una secuencialidad, los videos a la venta avanzan dicha secuencialidad, Internet puede establecer otras, etc.

El estudio semiótico de la japoanimación se torna, además, científicamente relevante, pues es producto de una realidad cultural significativamente diferente a la occidental, por lo que cabe preguntarse: ¿cuál es la resemantización local de la japoanimación, teniendo en cuenta que ellas es leída a partir de archivos de mundo occidentales, que podemos presuponer cualitativamente distintos a los mundos posibles que la generaron?. Es por ello, que el Departamento de Investigaciones Mediáticas, y de la Comunicación, de la Universidad de Chile, consciente de la relevancia del fenómeno descrito desarrolló una unidad de investigación sociosemiótica para la inteligibilización textual, y consumo cultural, de la japoanimación. Los investigadores Del Villar, Fajnzylber, con la colaboración de Lechuga, Lavrín, Letelier, Poblete, Hauva, Medel, Romo han dan fundamento al marco global de la descripción semiótica de los contenidos y manifestación visual de la japoanimación, el cual se expuso en el IV Congreso de la Federación Latinoamericana de Semiótica (La Coruña, España, 1999), por lo que corresponde presentar aquí una descripción semiótica realizada sobre fragmentos exploratorios respecto a protocolos de lectura empíricos, esto es, la segunda parte de la investigación descrita, en el contexto del saber cuantitativo ya adquirido, sintetizado y problematizado en las páginas precedentes.

Para poder entender el análisis semiótico de la lectura, cabe tener en cuenta el marco general dado por el análisis descriptivo de los textos televisivos de la japoanimación. Sabemos que un texto se interpreta a partir de los archivos de mundo posible de los lectores, pero sabemos también que el texto en sí mismo pone un marco interpretativo, generando varias vías interpretativas posibles, no existiendo tantas lecturas como lectores hay. Es por ello que partiremos sintetizando publicaciones anteriores respecto a los contenidos y sintaxis visual de la japoanimación.

\section{Contenidos de la japoanimación}

Debemos sintetizar que nuestras investigaciones detectan, en los textos fílmico televisivo estudiados, una forma de funcionamiento textual coherente y repetitiva diferente a los principios macrotextuales de la cultura chilena, de raigambre fundamentalmente católica. Esto se manifiesta en: a)una ausencia de intensionalidad individual en los personajes, pues no hay un objetivo o intencionalidad en sí, sino que una dependencia a condiciones de variados orígenes. Las categorías greimascianas de intencionalidad, objeto de deseo, y en la redefinición posterior de Greimas (1973) de disyunción/ conjunción entre un sujeto y un objeto, no tienen sentido. Así Goku, personaje principal de la Serie Dragón Ball Z, preferiría estar descansando en la tierra con su familia, pero cuando alguien altera el orden su furia lo hace ser el guerrero más poderoso, el legendario "Super Saiya- jin". "Goku no es guerrero en sí, sino que cumple un rol. Rol no adscrito a la vida eternamente, sino que según las condicionantes del entorno. Los objetivos, entonces, son fractales, interconexión de complejos, la conciencia, el acto volitivo en Goku, el contacto, la sensasión en Piccolo, etc.. Los 28 personajes Dragón Ball Z no son estables, sino que cambian. Lo mismo ocurre en las Sailor Moon.. La propuesta de los textos se acerca a la concepción budista de circularidad: se describen acontecimientos de cualquier duración, desde un sólo momento hasta una vida entera, y/o muchas vidas; los héroes, entonces nacen, mueren y renacen: pasando de un estado a otro; b)una ausencia de lo noción de sujeto, como sujeto que hace la vida: en los sujetos no habla el "yo" sino el "ello". El núcleo del proceso identificatorio son los otros, la situación, la coyuntura histórica. Los personajes del Dragón Ball Z son terrestres, extraterrestres, y androides, y muchas veces se fusionan lo que puede ser estable o 
momentánea. La fusión significa asumir una nueva forma corpórea que incluye a las dos o tres personalidades, incluso antitéticas que se fusionan, no estamos ante personajes, sino que ante fuerzas que toman diferentes configuraciones en función de un equilibrio, de un orden, que no es del orden de lo viviente, sino que incluye a la muerte; c) en la japoanimación se da, también, una correlación entre el mundo interior y el mundo exterior. La interioridad no está en lucha con el mundo externo, sino que se construye en una equivalencia con lo externo. Ello explica la fusión, no es el deber ser, como una identidad simbólica del "superyo", quien gesta la fusión; d) la oposición cuerpo/ mente propia de la ruptura epistémica del nuevo testamento, no tiene un lugar en el Dragón Ball Z. Los personajes toman diversas formas existiendo una equivalencia entre mente -cuerpo, y medio- ambiente; e)las polaridades buenos/ malos, o esto o aquello, están también ausentes de la japoanimación.

\section{Sintaxis fílmico-televisiva de la japoanimación}

La sintaxis audiovisual encontrada en los Dibujos Animados Japoneses Dragón Ball Z, Sailor Moon, y Pokémon tienen como reiteración organizativa los siguientes ejes descriptivos: a)menor hegemonía de la relación figura/ fondo que en la animación de Los Simpson; b)las estructuras narrativas son complejas: sus soportes, los personajes, son inestables, lo que imposibilita establecer programas y antiprogramas narrativos; tienen un gran número de personajes (Dragón Ball Z: 28, Pokémon: 150); no son lineales ni asimilables, como globalidad, a las categorías de Bremond (1966) de continuidad, enclave, ni enlace, pues se configuran relaciones de circularidad, que podemos definir, en el lenguaje de las ciencias cognitivas, como sistemas cognitivos enactivos: "las cuestiones relevantes que van surgiendo en cada momento de nuestra vida, no son predefinidas sino enactuadas: se las hace emerger desde un trasfondo, y lo relevante es aquello que nuestro sentido común juzga como tal, siempre dentro de un contexto" (Varela, 1996: 89), esto es, es la interconexión de partes, más la historia contingente, la configuración de lo percibible; y no son, tampoco, las narraciones sistemas cerrados, sino que abiertos; c)se configuran relaciones de interconexión códigas entre gestualidad, nudo narrativo, edición, música, iluminación, combinaciones cromáticas, movimientos de cámara; lo que une más a la videoanimación japonesa al videoclip y al videojuego que al cine; sin embargo se diferencia al video-clip en que no hay un rol hegemónico de la música como modalización del material fílmico televisivo; y d)una interrelación entre el universo pulsional y el universo simbólico.

Fajnzylber (1999) detecta una articulación pulsional constituida a partir de tres subconjuntos: tranquilidad, entrenamiento, combate, con una articulación pulsional coherente, asumida por todos los códigos, asumiéndose a su vez una relación de circularidad pulsional, lo que significa que la tensión crece del entrenamiento al combate, para reencontrar nuevamente su equilibrio, entre el Yang y el Ying. La conjunción de las polaridades del pensamiento budista leídas por la física cuántica, a través de Fritoj Capra (1984-1992), encuentran aquí su fiel expresión, la que es manifestada a través de todos sus componentes códigos. Un ejemplo (Fig. 1) de la articulación de todos los códigos para manifestar una pulsionalidad específica, referida al subconjunto combate es la siguiente (Fajnzylber, 2000: 9).

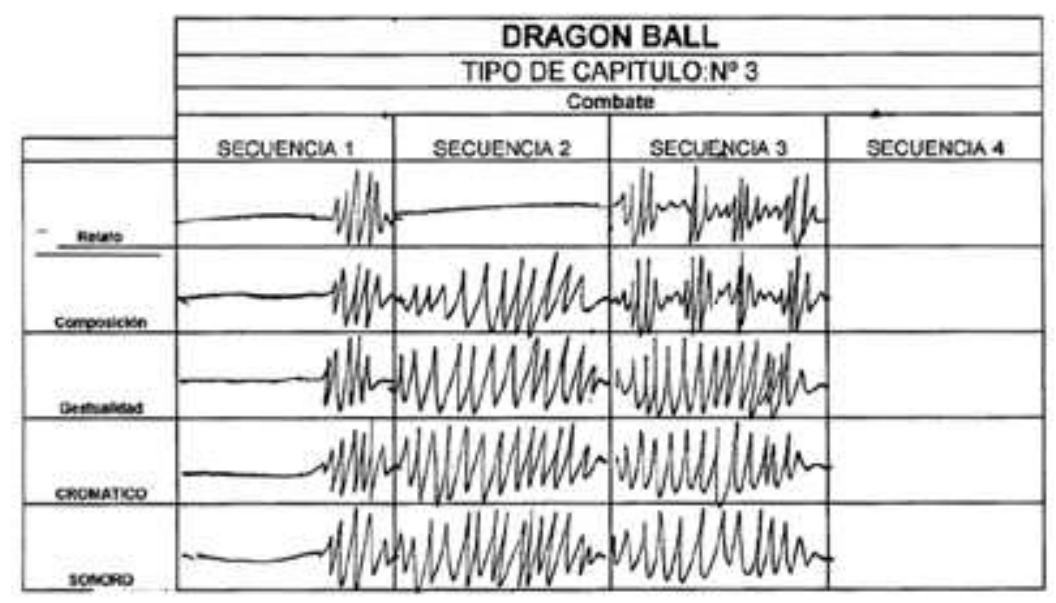


Esto significa que los códigos referidos a lo narrativo no sólo son las acciones de los personajes (relato) sino que los gestos y la composición de la imagen, donde la composición y la gestualidad acrecientan la tensión para el logro, en la secuencia 3 , de una máxima tensión, lo que va a la par con lo cromático y lo sonoro, implicando toda una ligazón imagen- cuerpo, a través de la forma de funcionamiento pulsional de las componentes códigas.

\section{Protocolos empíricos de lectura}

Las páginas precedentes permiten establecer el marco en el que se desarrolló la investigación exploratoria sobre los protocolos empíricos de niños y jóvenes de segmento socioeconómico medio de 7, 8 y 13 años de edad. Se les hizo dibujar libremente, y se realizaron entrevistas en profundidad respecto a su historia de vida, y su situación de consumo televisivo. Los dibujos recolectados por la investigadora Loreto Romo (Pokémon), y Rafael del Villar (Dragón Ball Z) no corresponden a una muestra estadística de la población, sólo se realizó con fines exploratorios de construir un modelo semiótico interpretativo de lectores prefigurados. Se tomaron como objeto de estudio aquellos referidos a la Serie Dragón Ball Z, y a Pokémon. De un total de 300 dibujos, 180 eran pokémon, y de ellos un tercio eran asociados a tranquilidad, un tercio a violencia, , y el otro tercio mediadores.

A nivel de la identificación simbólica, todos los protocolos interpretativos aprehendidos en los dibujos estudiados, y en las entrevistas en profundidad realizadas, no dicen relación con la matriz budista de los textos: a)la equivalencia mundo interior- mundo exterior que los textos plantean no es interpretada así por los niños y jóvenes chilenos estudiados, (figuras:2,3,4,5,6).. Los niños de 7 años tienen carencias dadas por depender del mundo adulto, pero al mismo tiempo por no saber operar en el mundo de los grandes: la fobia, la castración, la dependencia infraestructural de los padres y al mismo tiempo el paso al grupo de pares como fuente de gratificación emotiva. A eso hay que agregar las historias de vida particulares: carencias y fobias concretas. Las formas de vivir la oposición son diferentes: conflictos (figuras: $2,3,5$ ), expresión de un mundo hostil,(figuras: 2 y 3) conflictos virtuales (figuras: 4 y 6). Por otra parte, a los jóvenes de 8 a 13 años se les inserta otro espacio también conflictivo: su entrada en el mundo adulto a través de la sexualidad; la sociedad les prefigura un rol de género, pero ese rol pertenece al orden de la ensoñación, no teniendo un correlato concreto, la sexualidad, la seducción amorosa es algo que el sujeto no domina, no sabe operar en ella a nivel concreto; b)en ese espacio conflictivo (latente o fóbico), los sujetos estudiados pretenden tener un lugar: que el mundo externo sea una extensión del si mismo, construido bajo la figura del "yo", protegiéndose de esa exterioridad (figuras: 2, 3, 5,6). De allí la identificación con Goku o Gohan (Dragón Ball Z), o con alguno de los Pokémon (la mayor identificación es con Pikachu), donde la identificación opera ligada al poder: las habilidades de Goku, Gohan o Pikachu son objetos de poder que dan tranquilidad en un mundo de conflicto virtual o fóbico, o dan una idealidad que permite enfrentar, parecido al "ideal de yo", la violencia del mundo externo (figuras: 2,3,5). La identificación opera como energía interior (figura 4), o como fuerza real (figuras: 2,3), dependiendo ello de la historia de vida concreta, la identificación, en definitiva refuerza al yo; c)la ausencia de intencionalidad que plantean los textos de la japoanimación, es leída como intencionalidad por los sujetos estudiados. Se trata de un objetivo específico: tranquilidad (figuras: $3,4,6$ ), protección (figura 2) o agresión al mundo externo (figura 5); d)las no polaridades refuerza la identificación, pues los héroes no son perfectos; e)la mayoría de los dibujos recolectados no plantean un objeto real concreto, se trata de un espacio onírico. Los héroes son personajes de comics, esto es, dibujos, por lo que son ficticios, pero es en esa ficción (en esos poderes por sobre los demás de los héroes) donde se configura el espacio ficcional, que permite al sujeto suplir sus carencias, tranquilidad interior ante los conflictos virtuales (figuras:3,4,6), protección ante las amenazas del mundo externo (figuras: 2,5. El miedo, la rabia, la pena corresponde a la realidad, al mundo externo; esto es a las películas, a las series, a los noticieros según la encuesta .del Consejo Nacional de Televisión (1999). Luego, los dibujos nos dicen que la ficción no es un juego, no es una entretención en el sentido accional del término, donde los héroes sobrepasan la realidad. Lo real, películas, series, telenovelas, deportes, noticiero no gustan, en la exacta medida que es lo real, el conflicto mundo interior/ mundo exterior, y lo real es lo que el espacio de ficción del dibujo. De allí, la respuesta mayoritaria de los niños ante la encuesta del Consejo Nacional de Televisión (1999): 
"los dibujos no enseñan a pelear". La identificación tampoco opera según la encuesta en relación a conductas $\mathrm{y} / \mathrm{u}$ objetos deseados socialmente, lo que reafirma lo anterior, pues no es lo real concreto el objeto deseado, sino que un "objeto de poder" que permite desplazar el mundo interno en el mundo externo, un mundo que es una red de elementos, no relaciones de causa- efecto. La encuesta referida atribuía a "análisis respecto a las reglas culturales rígidas de lo establecido", y a "análisis respecto a principios o valores universales", como fuentes identificatorias de los personajes, un $20,6 \%$, y un $14,8 \%$ respectivamente. Ahora bien, como podemos interpretar estos datos cuantitativos a la luz del estudio semiótico de las entrevistas y de los dibujos. Creemos que es posible interpretarlo como manifestaciones del conflicto mundo exterior/ mundo interior ya especificado, de hecho son dos caras del mismo conflicto: las reglas establecidas/los valores universales respectivamente. De otra parte, el 39,1 \% señaló como variable de lectura de los personajes "análisis de los efectos concretos centrados en las consecuencias"; esto significa que el protocolo de lectura es analítico, es la inteligibilización del texto en toda su trama de relaciones. No se parte, en este caso de los valores del mundo interior ni de los valores del espacio externo, sino que de la realidad, la perspectiva es cognitivamente enactiva, en el sentido planteado por Varela ( 1996). Este proceso identificatorio no opera como una lectura pasiva de un programa televisivo, sino, como hemos señalado, a través de una realidad multimedial (CD Room, Videos, Filmes, VideoJuegos, Televisión, Comics, Cartas, Internet, etc), y a su vez con centros de venta de japoanimación, constituyéndose toda una red de acciones en torno a ellas: los niños y jóvenes cambian objetos de japoanimación y saberes culturales en torno a la japoanimación, en los entornos de los lugares de venta de japoanimación, en los lugares mismos, y en el colegio. En todos esos espacios se adquiere un poder- saber que se construye en la relación ante los demás. Esto significa, que el 39,1 \% de niños que se sitúan ante los personajes de la japoanimación como "análisis de los efectos concretos centrados en las consecuencias", lo que hacen es entender cognitivamente lo real a partir del real mismo, y el entenderlo les da una localización de poder, un espacio, en definitiva, sustituyendo en su grupo de pares el no lugar del mundo externo adulto.

Y en esto último radica el "goce" de la japoanimación, en su doble sentido, proceso identificatorio por una parte, pero, por otra, el "goce" de estar siempre atentos, todos los componentes códigos entregan una información, y esa información no es un artificio analítico intelictivo sino que pulsional. Es todo el cuerpo el que se encuentra implicado. Una entrevistada nos dijo: "los personajes de Los Simpson son siempre los mismos, Homero es siempre igual, en el Dragón Ball los personajes se mutan en sus principios constitutivos, no son estables, el nudo es estar siempre atento", nosotros agregaríamos, a través de una información que se expresa en varios códigos. Inteligibilizar Los Simpson presupone competencias de lectura fundamentalmente narrativas, de hecho la totalidad de niños consumidores de Los Simpson, son a su vez consumidores de libros. Dragón Ball Z y Pokémon presuponen competencias visuales multicódigas. $\mathrm{Y}$ ambos, son espacios pulsionalmente catárticos, lo que contrasta con el equilibrio y armonía de la mayoría de sus lectores para enfrentar la vida. La identificación onírica, de la que se habla, entonces, es un campo energético, que utiliza el mismo dispositivo cíclico pulsional de tranquilidad- entrenamientocombate descubierto por Fajnzylber ya citado, por lo que la actitud cognitiva enactiva de aprehender e inteligibilizar una red compleja de elementos no es un ejercicio lógico, sino que energético: inteligibilizar lo real es inteligibilizar fragmentos, entendidos como un "goce pulsional de desplazamiento energético. De allí, el aburrimiento con las películas y las seriales y las teleseries, pues tienen un sólo principio, lo narrativo, lo intelictivo. 

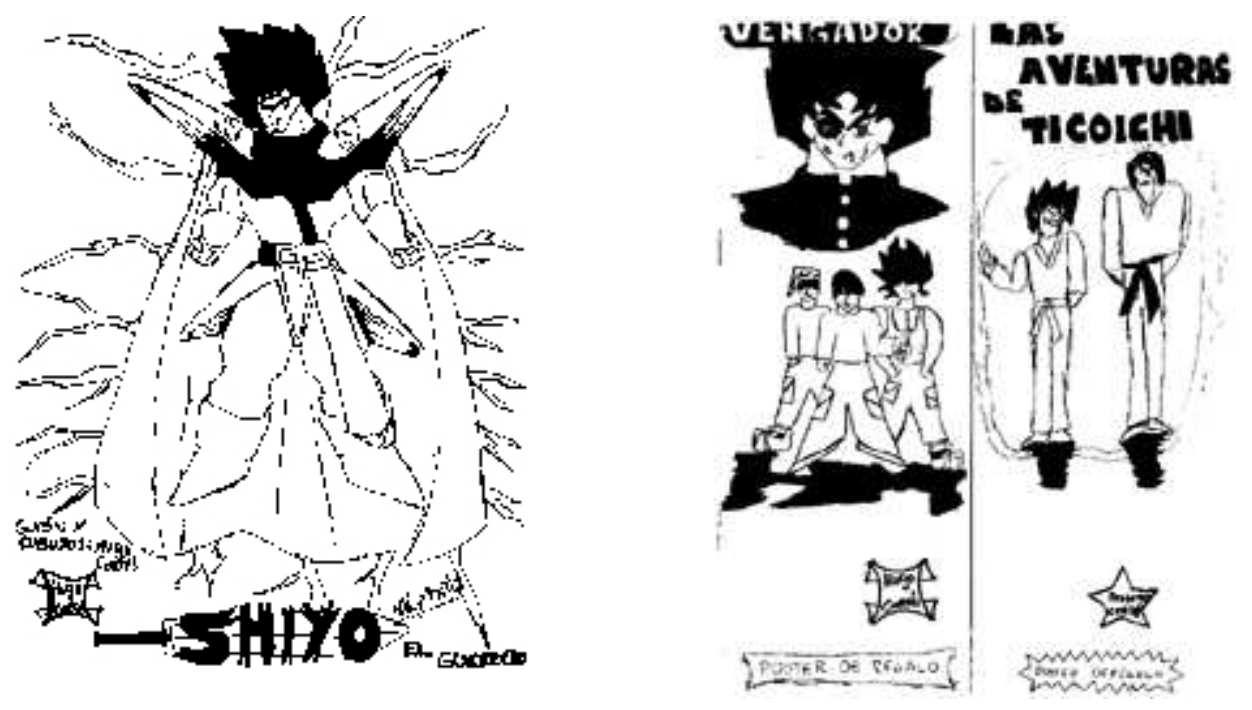

figura 2

figura 3
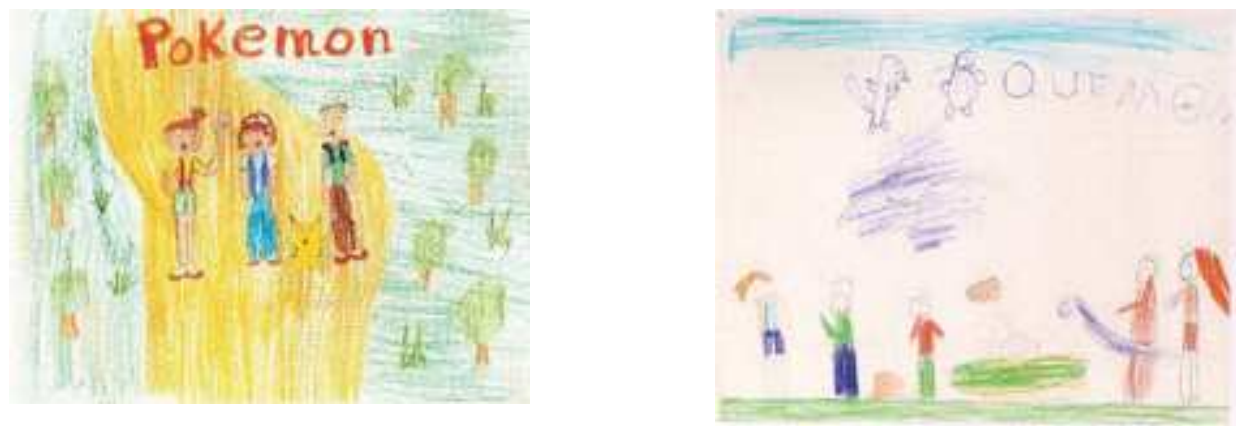

figura 4

figura 6

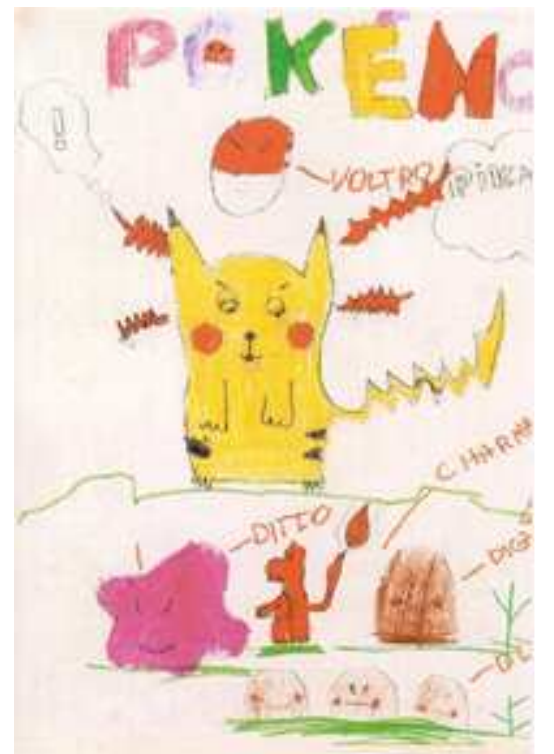

figura 5

AUMONT, J. (1990) "L'image", Paris, Ed. Nathan. (1992) Trad. Cast. "La imagen", Barcelona, Ed. Paidós.. (1997), El ojo interminable, Ed. Paidós, Barcelona. (1998), "El rostro en el cine", Ed, Paidós, Barcelona. AUMONT,MARIE,VERNET,BERgala,A (1987), "Estética del Cine", Barcelona, Ed.Paidós. 
BARBIERI, D. (1993), "Los lenguajes del comic", Barcelona, E. Paidós. CALABRESE,O., (1994), La era neobarroca", Madrid, Ediciones Cátedra. CAPRA, F. (1984- 1992), "El Tao de la física", Ed. Lui Cárcamo, Madrid. CASETTI,F.;Di CHIO;(1990),"Analisi del film", Milán, Ed. Bompiani. (1998), "Analisi della Televisione", Milano, Ed. Bompiani.

CONSEJO NACIONAL DE TELEVISIÓN, (1996), Encuesta Nacional de Televisión. (1997), "Consumo televisivo infantil, el Caso del Cable, Un estudio de observación Participante", Santiago, Chile. (1999), "La televisión y los niños en Chile: percepciones desde la audiencia infantil", Ed. CNTV, Santiago. CORTÉS, E., (1998), "El Gran Circo Teatro: una nueva forma de expresión", en Revista Chilena de Semiótica No 3, 1998, Internet, Ediciones Universidad de Chile, y Asociación Chilena de Semiótica(http://rehue.csociales.uchile.cl) CHION,M. (1982),"La voix au cinemá", Paris, Ed. de l'étoile. (1985), "Le son au cinemá", Paris, Ed. de l'étoile. (1985),"Ecrire un scénario", Paris, Ina-Cahiers du Cinemá. (1990), "L'audiovision", Paris, Ed. Nathan. (1998), "Le son", Paris,

Nathan.

DEL VILLAR, R. (1989) "Un outil sémiotique pour l'évaluation d'un vidéo educatif dans leur procès de gestationproduction" en "Educational Development No 2". Seúl. Korea. (1992), "La pragmatique d'un modèle sémiotique construit pour l'évaluation des vidéo-clip dans leur procès de gestation- production" en Libro "L'homme et ses signes" Tomo II/ editado por Deledalle, G. Berlin, Ed. Mouton de Gruyter.(1997),"Trayectos en Semiótica Fílmica/ Televisiva", Santiago, Ediciones

Dolmen.

DIRECCION DE ESTUDIOS SOCIOLÓGICOS, Universidad Católica de Chile, (1996), "Hábitos y usos en la televisión chilena". (1996), "La televisión en DESPINS, J.P.,(1996), "La música y el cerebro", Barcelona, Ed. Gedisa. FAJNZYLBER,V. (1999) "El lenguaje de los dibujos: una experiencia en semiótica animada", en "Revista Chilena de Semiótica No 4", Mayo 2000, Internet, Ediciones Universidad de Chile, y Asociación Chilena de Semiótica (http://rehue.csociales.uchile.cl), (2000), "El lenguaje de los dibujos animados", en Actas Congreso Iv Congreso Federación Latinoamericana de Semiótica, en Revista Signa, Madrid. GREIMAS.A.J.(1966),"Sémantique structurale", Paris, Ed. Larousse. (1970), "Du sens", Paris, Ed. Du Seuil. (1973), "Un problème de sémiotique narrative: les objets de valeur", en Revue "Langages No 31", Paris, Ed, Larousse. GUNTER, B. ; MC ALEER, J. (1997), "Children y television", London, Ed. Routledge. HAUVA, L. (2000), "Los Simpsons versus Dragón Ball Z), en Revista Chilena de Semiótica No 4, Septiembre 1999, Internet, Ed. Universidad de Chile, y Asociación Chilena de Semiótica (http://rehue.csociales.uchile.cl) KRISTEVA,J.(1974), "La révolution du langage poétique", Paris, Ed. Du Seuil. (1975), "La traversée des signes". Paris, Ed. Du Seuil. (1977),"Polylogue", Paris, Ed. Du Seuil. (1979), "Folle vérité", Paris, Ed. Du Seuil. (1980), "Pouvoirs de I'horreur", Paris, Ed. Du Seuil. (1983), "Histoires d'amour", Paris, Ed. Denoël. (1998), "Contre la dépression nationale", Paris, Ed.

Textuel.

LACAN,J., (1938), "La famille", Paris, Encyclopédie Francaise, Ed. A de Monzie. (1966) "Ecrits", Paris, Ed. du Seuil. (1973), "Les quatre concepts fondamentaux de la psychanalyse". Paris, Ed. du Seuil. (1981), "Les psychoses", Paris, Ed.

Seuil.

LAVRÍN, LECHUGA, LETELIER, POBLETE: "Semiótica de la japoanimación: análisis del Dragón Ball Z", en "Revista Chilena de Semiótica No 4", Mayo 2000, Internet, Ed. Universidad de Chile, y Asociación Chilena de Semiótica (http://rehue.csociales.uchile.cl)

LAX, W. ( 1997), en "Construcciones de la experiencia humana", Editado por Pakman, M. Volúmen II, Barcelona, Ed. Gedisa.

MANDELBROT, B. (1975), "Les objets fractals", Paris, Ed. Flammarion. (1997), "Fractales, hasard et finance", Paris, Ed. Flammarion.

MEDEL, I. (2000), "Japoanimación. Una travesía semiológica de la película Sailor Moon", en Revista Chilena de Semiótica No 4, Septiembre 1999, Internet, Ed. Universidad de Chile, y Asociación Chilena de Semiótica (http://rehue.csociales.uchile.cl)

METZ, CH. (1977), "Le signifiant imaginaire", Paris, Ed. 10/18. MOREIRA, H. (1994), "Cuerpo de mujer", Montevideo, Ed. Trilce. PETITOT-COCORDA; (1979), "Sur ce qui revient á la psychose", en "Folle verité", edit. por Julia Kristeva, Paris, Ed, du Seuil. (1985),"Morphogenèse du Sens", Paris, POSNER, R. (1993), "Believing, causing, intending: the basis for a hierarchy of sign concepts in the reconstruction of communication", en "Signs, search, and communication: semiotic aspects of artificial intelligence", Berlin- New York, Ed. Walter de REICH,W. (1970), "La fonction de l'orgasme", Paris, Ed. L'Arche. ROMO, L. (2000), "Lectura de la japoanimación a trvés del dibujo infantil; el caso Pokémon", en Revista Chilena de semiótica No 4, Septiembre 1999, Internet, Ed. Universidad de Chile, y Asociación Chilena de Semiótica (http://rehue.csociales.uchile.cl)

THOM, R. (1987), "Estabilidad estructural y morfogénesis", Barcelona, Editorial Gedisa. (1990), "Esbozo de una semiofísica", Barcelona, Editorial Gedisa. (1987), "Prédire n'est pad expliquer", Paris, Ed. Flanmarion. (1995), "Paraboles

et catastrophes",
Ed.

Flammarion.. 
VARELA, F. (1989), "Autonomie et connaissance", Paris, Ed. du Seuil. (1996), "Conocer", Barcelona, Ediciones Gedisa VARELA, F.; THOMPSON, E.; ROSCH, E. (1992), "De cuerpo presente", Barcelona, Ed. Gedisa. 